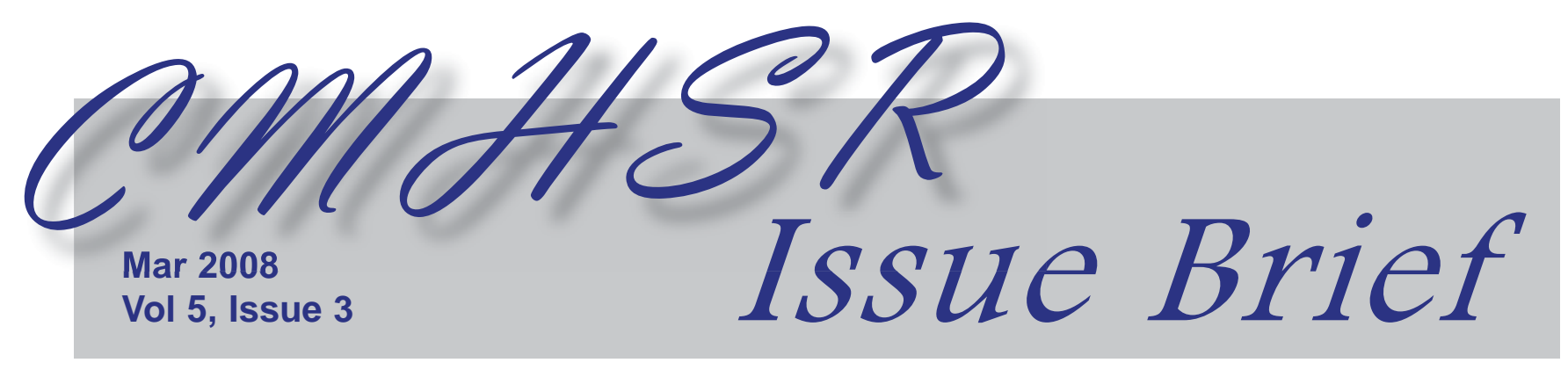

\title{
Pathways to Alcohol Use for Rural Latino Adolescents
}

Rosalie A. Torres Stone, Ph.D.

$\mathrm{T}$ he National Longitudinal Alcohol 1 Epidemiological Survey revealed that more than $40 \%$ of individuals who began drinking before age 15 developed alcohol dependence in later life. This is compared to $25 \%$ of those who began drinking at age 17 , and one tenth who began at age 21. ${ }^{1}$ Several factors associated with enhanced risk for early onset have been identified for adolescents in general, and Latino youth are at heightened risk for these factors. For example, culturally specific stressors associated with the immigration process exacerbate the risk for early initiation to alcohol use. ${ }^{2}$ However, little is known about culturally specific protective factors. Moreover, what we do know about risk and resilience is based primarily on research from large urban minority communities. There is a lack of research on alcohol use for immigrant Latino adolescents in rural settings. This brief examines 1) culturally specific risk factors for early onset alcohol use, 2) culturally specific protective factors, 3 ) the importance of considering non-urban communities and 4) future directions for research.

\section{Latino adolescents \& risk factors associated with alcohol use}

Although not all mediating mechanisms have been clearly identified, studies reveal that circumstances surrounding the migration experience (e.g., discrimination, acculturative stress, migration stressors and segmented assimilation) enhance risk for mental health problems and substance misuse behavior. ${ }^{2}$ Discrimination significantly predicts internalization and externalization problems among minority youth, including early onset of alcohol use. ${ }^{3}$ As Latino youth increase their interactions with the majority culture, they are more likely to experience discrimination, increased substance use and negative behavioral outcomes. ${ }^{4}$

\section{Studies \\ that acculturation processes place Latino youth at risk for problem behaviors. Acculturation refers to the process of cultural change experienced by members of a minority culture as they adapt to a new host majority culture and acculturative stress results from}

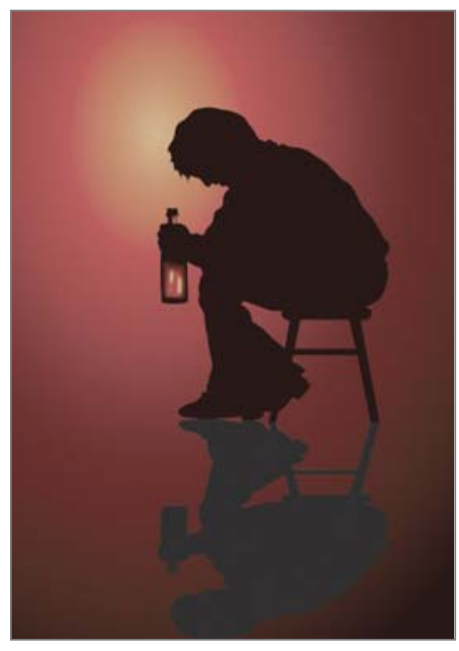
physiological and psychological changes brought about by acculturation related demands. ${ }^{5}$ For immigrant Latino families, this change is associated with learning the language, values and behaviors needed to function in the host culture.

The rapid adaptation of youth compared to parents often leads to increased intergenerational conflict, which undermines parental authority and strengthens the influence of deviant peers. ${ }^{6}$ As the family system weakens by the migration process, there is an increased risk for ineffective family monitoring and supervision, which increases youth's susceptibility to acculturation stressors and substance use. ${ }^{7}$ In addition, migration stressors associated with immigrants' exit from their countries of origin (i.e., temporary absence of one parent and isolation from informal support system) and entrance into the United States undermine family functioning and core extended family support. ${ }^{3}$ Research on Latino adolescents in large urban communities reveals that more acculturated youth are at increased risk for early onset of alcohol use. ${ }^{7}$ 


\section{Culturally-specific resilience factors}

Considerable research has been conducted on risk factors associated with behavioral problems among Latino youth; however, relatively little attention has been paid to resilience factors such as strong cultural identity and familism. Gonzales and her colleagues argue that youth who maintain a strong traditional ethnic identity show some resilience in the face of acculturative and immigration stressors. 8 Researchers argue that youth benefit from participating in the host culture, but also from retaining positive and protective traits of their native culture. Strong ethnic identity is related to enhanced self-esteem, a sense of belonging, and has been shown to moderate substance use risk for Latino adolescents (9). Likewise, traditional 'familism' has been a strong culturally-specific value among Latinos that serves to buffer Latino youth from negative substance use responses to acculturative stress. ${ }^{10}$ Familistic values and extended family orientation are generally thought to serve as protective sources of emotional and instrumental support for Latino adolescents. ${ }^{11}$ As this system weakens by the migration process, there is an increased risk for ineffective family monitoring and supervision, which increases youth's susceptibility to acculturation stressors and substance use. ${ }^{7}$

\section{Latinos in rural Massachusetts}

In Massachusetts, the rural Latino population increased by $77 \%$ between 1990 and 2000 and currently make up $2.2 \%$ of the rural population.12 Immigrant Latino youth living in non-metro areas are likely to face many of the same types of acculturation stressors as immigrant and minority youth in other settings. However, they face these stressors in an environment that provides fewer supports. Rural communities often have limited health care facilities and providers, and the existing services may lack the cultural competency to adequately serve their rapidly growing Latino populations. In addition, their parents are struggling with the combination of substandard employment and diminished cultural supports to help buffer acculturative stress.

\section{Future research}

Future research should identify the factors that influence the progression to regular use of alcohol for rural Latino immigrants and U.S. citizens of Hispanic descent. This research should be guided by a general theoretical model that specifically addresses the unique influences of general and culturally specific risk and resilience factors for these youth. It would also allow us to examine the interplay of these factors in the prediction of early onset of alcohol use. This would lead to more effective social and educational intervention strategies that can be developed to reduce the magnitude of this problem. The information gained would provide a better foundation for the design of the next iteration of culturally informed prevention and treatment programs that will more effectively target risk and protective factors on substance use for Latino immigrant adolescents residing in non-metropolitan areas.

\section{References}

1. Grant, B. F. \& Dawson, D. A. (1997). Age at onset of alcohol use and its association with DSM-IV alcohol abuse and dependence: Results from the national longitudinal alcohol epidemiologic survey. Journal of Substance Abuse, 9, 103-110.

2. Caetano, R. \& Galvan, F. H. (2001). Alcohol use and alcohol related problems among Latinos in the United States. In M. Aguirre-Molina \& R. E. Zambrana, (Eds). Health issues in the Latino community (pp. 383-412). San Francisco: Jossey-Bass.

3. Gibbons, F. X., Gerrard, M., Vande Lune, L.S., Wills, T.A., Brody, G., \& Conger, R.D. (2004). Context and cognitions: Environmental risk, social influence, and adolescent substance use. Personality and Social Psychology Bulletin, 30, 1048-1061.

4. N. Gonzales, N. \& Kim, L. (1997). Stress and coping in an ethnic minority context: Children's cultural ecologies. In S. Wolchik \& I. Sandler (Eds.). Handbook of children's coping: Linking theory and intervention (pp. 481-511). New York, NY: Plenum Press.

5. Berry, J. W., Uichol K., Minde, T. \& Mok, D. (1987). Comparative studies of acculturative stress. International Migration Review, 21, 491511.

6. Samaniego, R.Y., \& Gonzales, N.A. (1999). Multiple mediators of the effects of acculturation status on delinquency for Mexican American adolescents. American Journal of Community Psychology, 27, 189-210.

7. Gil, A. G., Vega, W.A., \& Biafora, F. (1998). Temporal influences of family structure and family risk factors on drug use initiation in a multiethnic sample of adolescents boys. Journal of Youth Adolescence 27, 373-393.

8. Gonzales, N. A., Knight, G. P., Birman, D., \& Sirolli, A. (2004). Acculturation and enculturation among Latino youth. In K. I. Maton, C. J. Schellenback, B. J. Leadbeater, \& A. L. Solarz (Eds.). Investing in children, youth, families, and communities: Strengths-based research and policy (pp. 285-302). Washington, DC: American Psychological Association.

9. Brook, J. S., Stuewig, J., \& Lecroy, C. W. (1998). A family based model of Hispanic adolescent substance use. Journal of Drug Addictions, $28,65-86$.

10. Andres G., Vega, W.A., \& Dimas, J. M. (1994). Acculturative stress and personal adjustment among Hispanic adolescent boys. Journal of Community Psychology. 22, 43-54.

11. Vega, W. A. (1990). Hispanic families in the 1980s: A decade of research, Journal of Marriage and Family. 52, 1015-1024.

12. Data from: DP-1: Profile of General Demographic Characteristics for Massachusetts: 1990 and 2000. From: http://www.census.gov/Press release/www/2001/tables/dp_ma_1990.xls and http://www.census. gov/Press-Release/www/2001/tables/dp_ma_2000.xls respectively.

Visit us on-line at www.umassmed.edu/cmhsr Send Comments to CMHSR@umassmed.edu 